\title{
SRH and HrQOL: does social position impact differently on their link with health status?
}

\author{
Cyrille Delpierre ${ }^{1,6^{*}}$, Michelle Kelly-Irving ${ }^{1,6}$, Mette Munch-Petersen², Valérie Lauwers-Cances ${ }^{3}$, Geetanjali D Datta ${ }^{4,5}$, \\ Benoît Lepage ${ }^{3}$ and Thierry Lang ${ }^{1,3,6}$
}

\begin{abstract}
Background: Self-rated Health (SRH) and health-related quality of life (HRQoL) are used to evaluate health disparities. Like all subjective measures of health, they are dependent on health expectations that are associated with socioeconomic characteristics. It is thus needed to analyse the influence played by socioeconomic position (SEP) on the relationship between these two indicators and health conditions if we aim to use them to study health disparities. Our objective is to assess the influence of SEP on the relationship between physical health status and subjective health status, measured by SRH and HRQoL using the SF-36 scale.

Methods: We used data from the French National Health Survey. SEP was assessed by years of education and household annual income. Physical health status was measured by functional limitations and chronic low back pain.

Results: Regardless of their health status, people with lower SEP were more likely than their more socially advantaged counterparts to report poor SRH and poorer HRQoL, using any of the indicators of SEP. The negative impact of chronic low back pain on SRH was relatively greater in people with a high SEP than in those with a low SEP. In contrast, chronic low back pain and functional limitations had less impact on physical and mental component scores of quality of life for socially advantaged men and women.

Conclusions: Both SRH and HRQOL were lower among those reporting functional limitations or chronic low back pain. However, the change varied according SEP and the measure. In relative term, the negative impact of a given health condition seems to be greater on SRH and lower on HRQOL for people with higher SEP in comparison with people with low SEP. Using SRH could thus decrease socioeconomic differences. In contrast using HRQoL could increase these differences, suggesting being cautious when using these indicators for analyzing health disparities.
\end{abstract}

Keywords: Subjective health indicators, Self-rated health, Quality of life, Socioeconomic position, Health inequalities

\section{Background}

Self-rated health (SRH) [1] and health-related quality of life (HRQoL) [2], which is defined as the perception of the impact of health problems on different spheres of life, including physical, mental, and social aspects, are two outcome measures used to assess health status. Because they are self-reported, they are inexpensive and easy to use, and it has been shown that SRH $[1,3,4]$ and in a lesser measure HRQoL [5-9], are independent predictors of subsequent mortality and morbidity. As a consequence, SRH and more recently HRQoL $[10,11]$,

\footnotetext{
* Correspondence: cyrildelpierre@yahoo.fr

'Inserm, UMR1027, Toulouse, F-31073, France

Full list of author information is available at the end of the article
}

have been used as an alternative to mortality or morbidity for measuring health disparities. As an example, Mackenbach et al. compared social inequalities in health between 22 European countries using mortality and $\mathrm{SRH}$ as health measures [12]. Interestingly, the magnitude of social inequalities was greater by using mortality rather than SRH. By considering mortality as the "gold standard" for measuring social inequalities in health, these results suggest that using SRH as measure of health might underestimate social disparities in health.

Contrary to mortality, SRH and HRQoL are both dependent on individual expectations. SRH can be considered as a balance between one's actual health and the best health that one could expect for oneself [13], while
C Biomed Central

() 2011 . Delpierre et al; licensee BioMed Central Ltd. This article is published under license to BioMed Central Ltd. This is an Open Access article distributed under the terms of the Creative Commons Attribution License (http://creativecommons.org/licenses/by/2.0), which permits unrestricted use, distribution, and reproduction in any medium, provided the original work is properly cited. 
HRQoL refers to the physical, psychological and social domains of health which are influenced by a person's experiences, beliefs, expectations and perceptions [2]. The way people rate their health depends therefore on their expectations of what their health should be. The expectations that people have vary according to several factors, such as socioeconomic position (SEP) and cultural or social issues $[14,15]$, which may bring about differences in reporting health status or quality of life for the same health condition. As expectations seem to be higher among people with high SEP [16], the same disease may have a more negative impact on SRH among them than among people with low SEP. In fact, recent studies conducted in the U.S. have shown that the relative impact on SRH of a given chronic condition was greater in people with a higher years of education than in those with less education [17-19], suggesting that using SRH as a measure of health could lead to underestimation of the magnitude of health inequalities existing between socioeconomic groups, as observed by Mackenbach et al. [12]. At the opposite, some others studies conducted on Canadian samples have shown no such interaction or a relative lower impact of health condition on SRH [20,21].

As suggested by Smith et al. "understanding if people from different SES background interpret levels of SRH differently is essential for..... comparing health inequalities with SRH" [21]. This type of variation by SEP may be relevant for subjective health indicators other than $\mathrm{SRH}$ as well. One such indicator is the SF-36 scale which is a general questionnaire measuring healthrelated quality of life through its physical and mental components. It has been shown that SRH was associated with all dimensions of the SF-36 [22], suggesting that SRH may include perceptions of a range of physical, mental and social factors. Because SRH and the SF-36 scale measure related concepts and because SRH seems to vary according to SEP given health status, exploring the potential influence of SEP on HRQoL may be of interest.

Data on the influence of SEP on the relationship between HRQoL and health conditions are limited. However Sacker et al. have shown that the negative impact of coronary heart disease on SF-36 was greater among lower-grade civil servants, suggesting that, contrary to what is observed with SRH, the negative impact of a given health condition may be higher for people in a low socioeconomic position [23]. The influence of SEP on the relationship between health conditions and subjective health may be thus different according to indicators used to measure subjective health. The aim of this study was thus to assess if the SEP had an influence on the relationship between health conditions and subjective health status, measured by SRH and an indicator of
HRQoL, the SF-36 questionnaire, and to assess if this influence was different on SRH and on SF-36.

\section{Methods}

\section{Study population and sample design}

The French data comes from the National Health Survey (NHS) (http://www.cnis.fr/ind_doc.htm), the only source of systematic statistical data on the health, health-care consumption and socioeconomic characteristics of French households. This study has been described in detail elsewhere [24]. Briefly, data were collected through a multilevel, stratified, random survey of households that, on the basis of data from the 1999 national population census, are representative of the French population. People who live in institutions (e.g. retirement homes, religious communities, prisons and hospitals), in mobile homes or who are homeless are not included, therefore almost $98 \%$ of the entire population is covered by the survey [24]. Using a combination of face-to-face interviews and self-administered questionnaires, the NHS includes data at both individual and household levels, including information about demographic and socioeconomic characteristics and health status, complementary insurance coverage and medical care consumption.

A new data collection was carried out between October 2002 and September 2003 and constitutes our sample. People were interviewed in five waves, throughout the year to account for seasonal variability. Three faceto-face interviews were conducted at one-month intervals. A self-administered health questionnaire was given to each participant after the first visit and was collected at the second or the third visit. The overall response rate during the 2003 NHS survey was $>85 \%$. The global sample was composed of 16,821 households, representing 40,796 individuals.

We excluded participants younger than 18 years old before conducting analyses $(\mathrm{N}=9800)$. Among the 30996 adults, we restricted our analyses to participants who responded to the three visits and who completed the self-administered health questionnaire $(\mathrm{N}=26341)$. We then excluded those who were considered by the interviewer as not able to complete the questionnaire ( $\mathrm{n}$ =513). We also excluded people claiming full state health-care coverage (pregnant women, people with serious and high-cost disease, disabled persons) who may represent a sub population with specific health expectations compared with general population due to the existence of severe disease $(n=4043)$. The final sample consisted of 10,093 men and 11,692 women.

\section{Socioeconomic position}

SEP was assessed by using two indicators: years of education, categorized as less than 12 years, 12 years, and 
more than 12 years and annual household income per consumption unit. Annual household income per consumption unit corresponds to the total income reported within the household divided by the number of consumption units of the household. The OCDE scale gives a weight of 1 to the first member of the household, a weight of 0.5 for any other adult and a weight of 0.3 for any child of less than 14 years. It was categorized in 4 classes according to quartiles (< Euro 9,900; 9,90014,300, 14,300-20,400, > = Euro 20,400)

\section{Physical health conditions}

We considered physical health conditions available in the study data which are known to be strong determinants of SRH and quality of life: functional limitations and chronic low back pain $[22,25,26]$. These two health conditions were not measured in an "objective" way but used diagnostic validated questionnaire.

Functional limitations (FL) were self-reported and assessed with the activities of daily living scale (ADLs), instrumental activities of daily living scale (IADLs), mobility and upper/lower body strength [27]. Participants who reported some difficulty, much difficulty or who were unable to do one of the activities were considered to have FL.

Chronic low back pain was assessed through a validated self-administered questionnaire, the French version of the Nordic questionnaire for the analysis of musculoskeletal symptoms [28]. This questionnaire includes 4 questions on presence and duration of low back pain during the past year before study, and type of pain. Participants who reported at least one event of low back pain for more than 30 days (at least 30 days but not daily, or pain everyday) were considered as having chronic low back pain [29].

\section{Subjective health status}

Subjective health status was evaluated with two indicators: Self-rated health and health-related quality of life.

SRH ("How is your general health?") was measured by using the WHO recommended version asking participants to rate their health as very good, good, fair, poor or very poor. The responses were dichotomized in our analyses: individuals reporting very good or good health were classified as having good SRH and those reporting fair or poor or very poor health as having poor SRH.

HRQoL was measured with the SF-36 scale. The SF36 has been validated and described in detail elsewhere [30]. It covers issues relating to physical, psychological and social functioning and is coded into eight scales: general health perceptions (5 items), physical functioning (10 items), role limitations due to physical functioning ( 4 items), bodily pain ( 2 items), general mental health (5 items), role limitations due to emotional problems (3 items), vitality ( 4 items) and social functioning ( 2 items). The remaining item relating to change in health is not scored as a separate dimension. These eight scales can be summarized into physical and mental functioning component scores (the Physical Component Summary (PCS), and the Mental Component Summary (MCS)) [30], which were used as indicators of quality of life in the study. Jenkinson suggested US scoring be adopted throughout the world [31]. Thus, the PCS and MCS were scaled using general US population norms to have mean $+/$ - standard deviation values of $50+/$ - 10. A higher score indicates a better quality of life.

\section{Statistical analysis}

SEP may operate differentially on subjective health in men and women [32-36], and according to age. Therefore, all our analyses were run separately for men and women and all were adjusted on age.

We were interested in studying whether education or income could modify the association between SRH/ HRQoL and health conditions, and thus influence the measure of health inequalities by using subjective measures of health. Therefore we focused on the interaction effect between socioeconomic position and health conditions on SRH and HRQoL.

Regarding SRH, to test this interaction, we constructed logistic regression models with the probability of reporting poor SRH as the outcome and included terms for socioeconomic position (education and income separately), the health condition, and the interaction between education and the health condition (example of the model with education and FL: poor $\mathrm{SRH}=$ Age $+\mathrm{FL}+$ education + education*FL). As a statistical interaction was detected for most conditions, the results were presented after stratification on socioeconomic position (education and income). In tables, the relationship between health conditions and SRH was analyzed and presented using logistic regression adjusted on age, for each socioeconomic group.

Using the same methodological approach, with MCS and PCS as the outcome, we constructed multiple linear regression models that included terms for each SEP indicator separately, the health condition, and the interaction between the SEP indicator and the health condition. Again as a statistical interaction was detected for most conditions, the results were presented after stratification on socioeconomic position. In tables, the relationship between health conditions and PCS/MCS was analyzed and presented using multiple linear regression models adjusted on age, for each socioeconomic group.

We used sampling weights to produce our weighted estimates and sampling errors (SEs). Sampling weights were used to correct for systematic nonresponse bias. This procedure allows data to be weighted in an 
inversely proportional relationship to the nonresponse probabilities of individuals to the survey and the selfadministered questionnaires, in the aim to perfectly reflect the French population.

Statistical analyses were performed using SAS (version 9.1, SAS Institute, Cary, NC).

\section{Results}

\section{Socioeconomic position and health}

The social gradient was associated with poorer SRH and poorer quality of life in both men and women (Table 1). Men and women with lower years of education were more likely to have FL and chronic low back pain compared with those with more than 12 years of education (Table 1). Men with a lower level of income were more likely to have FL and chronic low back pain than those with higher level of income. Women with a lower level of income were more likely to have FL than those with higher level of income, but no gradient was observed for chronic low back pain. Social gradient was steeper for FL than for chronic low back pain, with both socioeconomic indicators (education and income).

\section{Interaction of socioeconomic position and health conditions on SRH (Tables 2 and 3)}

FL and chronic low back pain were associated with poorer SRH using each indicator of SEP in both men and women.

Among men, regarding the influence of years of education, the relative impact of chronic low back pain on SRH was higher for those with more than 12 years of education than for those with less than 12 years (interaction test $\mathrm{P}=$ 0.05 ), as for those with 12 years of education, the interaction test being non significant (interaction test $\mathrm{P}=0.12$ ) (Table 2). In age-adjusted models, the relative increase in the proportion of men reporting poor SRH in the case of

Table 1 Relationships between Socioeconomic Position and Health, in Men and Women; National Health Survey

\begin{tabular}{|c|c|c|c|c|c|}
\hline \multirow[b]{3}{*}{ Education (missing $=720$ ) } & Poor SRH (\%) & PCS (Mean) & MCS (Mean) & Functional limitations (\%) & Chronic low back pain (\%) \\
\hline & \multicolumn{5}{|c|}{ MEN } \\
\hline & & & & & \\
\hline$<12$ years $(\mathrm{n}=2432)$ & 26.1 & 50.2 & 50.3 & 14.4 & 15.3 \\
\hline 12 years $(n=3688)$ & 17.9 & 51.5 & 50.4 & 10.1 & 15.7 \\
\hline$>12$ years $(n=3253)$ & 10.6 & 53.3 & 51.3 & 7.6 & 12.3 \\
\hline P-value* & $<0.0001$ & $<0.0001$ & 0.009 & $<0.0001$ & 0.001 \\
\hline Missing (N) & 6 & 1747 & 1747 & 3 & 1611 \\
\hline \multicolumn{6}{|l|}{ Annual income $(€)$} \\
\hline$<9,900(n=2380)$ & 24.8 & 50.5 & 49.7 & 14.1 & 15.2 \\
\hline $9,900-14,300(n=2515)$ & 19.6 & 51.7 & 50.3 & 10.9 & 13.8 \\
\hline $14,300-20,400(n=2529)$ & 14.4 & 52.3 & 50.9 & 8.0 & 14.2 \\
\hline$>=20,400(n=2669)$ & 8.4 & 53.6 & 51.3 & 6.4 & 11.8 \\
\hline P-value* & $<0.0001$ & $<0.0001$ & $<0.0001$ & $<0.0001$ & 0.02 \\
\hline \multirow[t]{2}{*}{ Missing (N) } & 7 & 1855 & 1855 & 3 & 1723 \\
\hline & \multicolumn{5}{|c|}{ WOMEN } \\
\hline \multicolumn{6}{|l|}{ Education (missing $=784$ ) } \\
\hline$<12$ years $(\mathrm{n}=3650)$ & 30.5 & 48.8 & 47.7 & 24.7 & 19.6 \\
\hline 12 years $(n=3768)$ & 22.1 & 51.2 & 47.7 & 16.5 & 20.1 \\
\hline$>12$ years $(n=3490)$ & 16.4 & 52.0 & 48.4 & 14.5 & 16.2 \\
\hline P-value* & $<0.0001$ & $<0.0001$ & 0.02 & $<0.0001$ & 0.001 \\
\hline Missing (N) & 5 & 2131 & 2131 & 2 & 1924 \\
\hline \multicolumn{6}{|l|}{ Annual income $(€)$} \\
\hline$<9,900(n=3092)$ & 28.1 & 49.7 & 46.8 & 22.8 & 17.7 \\
\hline $9,900-14,300(n=2981)$ & 23.4 & 50.5 & 47.4 & 19.4 & 19.3 \\
\hline $14,300-20,400(n=2830)$ & 19.7 & 51.7 & 48.4 & 15.9 & 18.2 \\
\hline$>=20,400(n=2789)$ & 15.4 & 52.1 & 48.8 & 10.6 & 17.4 \\
\hline P-value* & $<0.0001$ & $<0.0001$ & $<0.0001$ & $<0.0001$ & 0.39 \\
\hline Missing (N) & 5 & 2211 & 2211 & 3 & 2016 \\
\hline
\end{tabular}

SRH: Self Rated Health; PCS: SF-36 Physical Component Summary; MCS: SF-36 Mental Component Summary \% adjusted for age ${ }^{*}$ Global chi-square 
Table 4 HRQoL Score According to the Presence or Absence of Health Conditions by Socioeconomic Position, Among Men; National Health Survey

\begin{tabular}{|c|c|c|c|c|c|}
\hline & \multicolumn{5}{|c|}{ PCS } \\
\hline & \multicolumn{4}{|c|}{ Years of education } & \multirow[b]{2}{*}{ Interaction test } \\
\hline & $<12$ years & & & $>12$ years & \\
\hline \multicolumn{6}{|l|}{ Functional limitations, mean ${ }^{a}$} \\
\hline No & 51.5 & \multicolumn{2}{|c|}{52.5} & 53.9 & $0.11^{\mathrm{b}}$ \\
\hline Yes & 42.4 & \multicolumn{2}{|c|}{42.4} & 45.7 & $0.31^{\mathrm{c}}$ \\
\hline Regression coefficient $^{\dagger}$ & -8.7 & \multicolumn{2}{|c|}{-10.3} & -8.4 & \\
\hline \multicolumn{6}{|l|}{ Chronic low back pain, mean ${ }^{\text {a }}$} \\
\hline No & 51.5 & \multicolumn{2}{|c|}{52.7} & 54 & $0.28^{b}$ \\
\hline Yes & 43.8 & \multicolumn{2}{|c|}{45.6} & 48.8 & $0.0002^{c}$ \\
\hline Parameter $^{\dagger}$ & -7.6 & \multicolumn{2}{|c|}{-7.1} & -5.4 & \\
\hline \multicolumn{6}{|l|}{ Interaction test } \\
\hline & \multicolumn{4}{|c|}{ Income level $(€)$} & \\
\hline & $<9,900$ & $9,900-14,300$ & $14,300-20,400$ & $>=20,400$ & Interaction test \\
\hline \multicolumn{6}{|l|}{ Functional limitations, mean ${ }^{a}$} \\
\hline No & 52.0 & 52.7 & 53.0 & 54.1 & $0.02^{d}$ \\
\hline \multirow[t]{2}{*}{ Yes } & 41.2 & 43.6 & 45.1 & 45.3 & $0.0002^{\mathrm{e}}$ \\
\hline & & & & & $0.01^{f}$ \\
\hline Regression coefficient $^{\dagger}$ & -10.8 & -8.9 & -7.9 & -8.9 & \\
\hline \multicolumn{6}{|l|}{ Chronic low back pain, mean ${ }^{a}$} \\
\hline No & 51.8 & 52.6 & 53.2 & 54.4 & $0.004^{d}$ \\
\hline \multirow[t]{2}{*}{ Yes } & 43.5 & 46.4 & 47.6 & 47.8 & $0.0002^{e}$ \\
\hline & & & & & $0.02^{f}$ \\
\hline \multirow[t]{4}{*}{ Regression coefficient $^{\dagger}$} & -8.1 & -6.1 & -5.8 & -6.6 & \\
\hline & \multicolumn{5}{|c|}{ MCS } \\
\hline & \multicolumn{5}{|c|}{ Years of education } \\
\hline & $<12$ years & & & $>12$ years & Interaction test \\
\hline \multicolumn{6}{|l|}{ Functional limitations, mean ${ }^{a}$} \\
\hline No & 50.8 & & & 51.5 & $0.85^{\mathrm{b}}$ \\
\hline Yes & 47.2 & & & 49.3 & $0.12^{c}$ \\
\hline Regression coefficient $^{\dagger}$ & -4.1 & & & -2.0 & \\
\hline \multicolumn{6}{|l|}{ Chronic low back pain, mean ${ }^{a}$} \\
\hline No & 50.8 & & & 51.8 & $0.85^{\mathrm{b}}$ \\
\hline Yes & 47.7 & & & 47.7 & $0.19^{c}$ \\
\hline \multirow[t]{3}{*}{ Regression coefficient $^{\dagger}$} & -3.1 & & & -4.2 & \\
\hline & & Incol & vel $(€)$ & & \\
\hline & $<9,900$ & $9,900-14,300$ & $14,300-20,400$ & $>=20,400$ & Interaction test \\
\hline \multicolumn{6}{|l|}{ Functional limitations, mean ${ }^{a}$} \\
\hline No & 50.4 & 50.6 & 51.2 & 51.4 & $0.11^{\mathrm{d}}$ \\
\hline Yes & 45.9 & 47.5 & 48.4 & 49.2 & $0.06^{\mathrm{e}}$ \\
\hline & & & & & $0.02^{f}$ \\
\hline Regression coefficient $^{\dagger}$ & -4.6 & -3.2 & -2.8 & -2.0 & \\
\hline Chronic low back pain, mear & & & & & \\
\hline No & 50.3 & 50.8 & 51.4 & 51.7 & $0.31^{d}$ \\
\hline
\end{tabular}


Table 4 HRQoL Score According to the Presence or Absence of Health Conditions by Socioeconomic Position, Among Men; National Health Survey (Continued)

\begin{tabular}{|c|c|c|c|c|c|}
\hline Yes & 46.2 & 47.5 & 48.5 & 48.3 & $0.16^{e}$ \\
\hline & & & & & $0.35^{f}$ \\
\hline Regression coefficient $^{\dagger}$ & -4.0 & -3.3 & -3.1 & -3.3 & \\
\hline \multicolumn{6}{|l|}{${ }^{\mathrm{a}}$ : mean adjusted for age } \\
\hline \multicolumn{6}{|c|}{$\begin{array}{l}\text { b: Interaction between health status and years of education: results for years of education }=12 \text { years compared with years of education }<12 \text { years; model } \\
\text { adjusted for age }\end{array}$} \\
\hline \multicolumn{6}{|c|}{$\begin{array}{l}\text { c: Interaction between health status and years of education: results for years of education }>12 \text { years compared with years of education }<12 \text { years; model } \\
\text { adjusted for age }\end{array}$} \\
\hline \multicolumn{6}{|c|}{$\begin{array}{l}\text { d: Interaction between health status and income level: results for income level between 9,900-14,300 } € \text { compared with income level }<9,900 € \text {; model adjusted } \\
\text { for age }\end{array}$} \\
\hline \multicolumn{6}{|c|}{$\begin{array}{l}\text { e: Interaction between health status and income level. Results for income level between } 14,300-20,400 € \text { compared with income level }<9,900 € \text {; model adjusted } \\
\text { for age }\end{array}$} \\
\hline \multicolumn{6}{|c|}{ f: Interaction between health status and income level. Results for income level $>=20,400 €$ compared with income level $<9,900 € ;$ model adjusted for age } \\
\hline
\end{tabular}

education than in those with the lowest length (Interaction test $P=0.07$ ). A similar trend was not observed with level of income.

Regarding the influence of SEP on the relationship between health conditions and MCS score, the decrease of MCS score in the case of chronic low back pain or FL was smaller in women with income higher than $9,900 €$ compared with women with an income below $9,900 €$. No influence of education was observed.

\section{Discussion}

To our knowledge, this is one of the first studies analyzing the influence of SEP on the relationship between physical health conditions and SRH on the one hand and a generic measure of HRQoL, the SF-36 questionnaire, on the other hand. Our results suggest that SEP influences the impact of health conditions, like FL or chronic low back pain, on subjective health in a different way according to whether it is measured by SRH or HRQoL. Compared with people with low SEP, some health conditions like chronic low back pain seem to have a greater negative impact on SRH in socially advantaged people, but the opposite occurred for quality of life. The strength of this interaction varied according to the indicator used to measure health conditions as well as the indicator used to define SEP.

An important limitation of our study is that health conditions were self-reported, and may be susceptible to misreporting [37]. However, we mainly studied chronic disabling diseases, assessed using valid questionnaires or a standardized definition that may be less susceptible to this type of misreporting [38]. Moreover, self reports could be reasonably accurate for certain chronic conditions $[39,40]$. Haapanen et al. showed that agreement between questionnaire data and medical records may be good for chronic diseases that have a clear definition [41]. As we used chronic health conditions and valid questionnaires or definitions to measure them, we believe that the proportion of misreporting is low, and unlikely to explain the opposite directions for SRH and HRQoL. Idler et al. showed that knowledge of a chronic illness strengthened the association between SRH and mortality [42]. Thus, use of patient-reported health conditions could constitute an appropriate indicator for analyzing the association between health conditions and subjective health. However, future studies are needed to examine the influence of SEP on the relationship between subjective health and objective health or "true health", assessed through more objective measures or by using multiple indicators linear structural equation models with latent variables as done by Shmueli et al. [43].

Another limitation is that some items used to evaluate FL are components of PCS score of the SF36 questionnaire. As low educated people have higher number of FL than high educated men, their PCS score should be poorer and could explain why PCS scores are poorer among lower educated people in case of disease. Although FL is subsumed within the concept of HRQoL measured by the SF-36 questionnaire, these two measures are not exactly the same. As an illustration, some works have shown that FL was a predictive factor of HRQoL, justifiying that FL and HRQoL are two different concepts $[22,25,26]$. In our study correlations between PCS score and FL were -0.38 in men and -0.49 in women. Therefore we do not think that this correlation is likely to explain totally the lower decrease of PCS score observed among people with high SEP. Moreover the same interaction is observed with MCS score for which no correlations were found between FL and MCS. Finally, we observed a lower decrease of PCS score for men with higher SEP in case of chronic low back pain, which is a different measure than the SF-36 questionnaire.

Another limitation is that tests of interaction have usually classically low power $[44,45]$. It is thus likely that some of interactions tests we performed lacked 
Table 5 HRQoL Score According to the Presence or Absence of Health Conditions by Socioeconomic Position, Among Women; National Health Survey

\begin{tabular}{|c|c|c|c|c|c|}
\hline & \multicolumn{5}{|c|}{ PCS } \\
\hline & \multicolumn{4}{|c|}{ Years of education } & \multirow[b]{2}{*}{ Interaction tes } \\
\hline & $<12$ years & & & $>12$ years & \\
\hline \multicolumn{6}{|l|}{ Functional limitations, mean ${ }^{a}$} \\
\hline No & 51.2 & & & 53.3 & $0.36^{\mathrm{b}}$ \\
\hline Yes & 41.4 & & & 44.2 & $0.25^{\mathrm{c}}$ \\
\hline Regression coefficient $^{\dagger}$ & -9.4 & & & -9.2 & \\
\hline \multicolumn{6}{|l|}{ Chronic low back pain, mean ${ }^{a}$} \\
\hline No & 50.1 & & & 52.9 & $0.98^{\mathrm{b}}$ \\
\hline Yes & 43.8 & & & 47.7 & $0.07^{c}$ \\
\hline Parameter $^{\dagger}$ & -6.1 & & & -5.4 & \\
\hline \multicolumn{6}{|l|}{ Interaction test } \\
\hline & \multicolumn{4}{|c|}{ Income level $(€)$} & \\
\hline & $<9,900$ & $9,900-14,300$ & $14,300-20,400$ & $>=20,400$ & Interaction test \\
\hline \multicolumn{6}{|l|}{ Functional limitations, mean ${ }^{a}$} \\
\hline No & 51.9 & 52.6 & 53.2 & 53.2 & $0.06^{d}$ \\
\hline \multirow[t]{2}{*}{ Yes } & 42.3 & 42.1 & 44.0 & 43.4 & $0.51^{\mathrm{e}}$ \\
\hline & & & & & $0.69^{f}$ \\
\hline Regression coefficient $^{\dagger}$ & -9.7 & -10.3 & -9.4 & -9.6 & \\
\hline \multicolumn{6}{|l|}{ Chronic low back pain, mean ${ }^{a}$} \\
\hline No & 50.9 & 51.8 & 52.8 & 53.4 & $0.71^{d}$ \\
\hline \multirow[t]{2}{*}{ Yes } & 44.7 & 45.8 & 47.2 & 47.0 & $0.33^{e}$ \\
\hline & & & & & $0.76^{f}$ \\
\hline \multirow[t]{4}{*}{ Regression coefficient $^{\dagger}$} & -6.2 & -5.9 & -5.6 & -6.4 & \\
\hline & \multicolumn{5}{|c|}{ MCS } \\
\hline & \multicolumn{5}{|c|}{ Years of education } \\
\hline & $<12$ years & & & $>12$ years & Interaction test \\
\hline \multicolumn{6}{|l|}{ Functional limitations, mean ${ }^{a}$} \\
\hline No & 48.5 & & & 48.9 & $0.39^{\mathrm{b}}$ \\
\hline Yes & 45.0 & & & 45.0 & $0.57^{c}$ \\
\hline Regression coefficient $^{\dagger}$ & -3.3 & & & -4.3 & \\
\hline \multicolumn{6}{|l|}{ Chronic low back pain, mean ${ }^{a}$} \\
\hline No & 48.2 & & & 48.8 & $0.37^{b}$ \\
\hline Yes & 44.6 & & & 46.1 & $0.26^{c}$ \\
\hline \multirow[t]{3}{*}{ Regression coefficient $^{\dagger}$} & -3.5 & & & -2.9 & \\
\hline & & Inco & vel $(€)$ & & \\
\hline & $<9,900$ & $9,900-14,300$ & $14,300-20,400$ & $>=20,400$ & Interaction test \\
\hline \multicolumn{6}{|l|}{ Functional limitations, mean ${ }^{a}$} \\
\hline No & 47.8 & 48.0 & 48.8 & 49.0 & $0.07^{d}$ \\
\hline \multirow[t]{2}{*}{ Yes } & 43.5 & 44.9 & 45.9 & 46.5 & $0.06^{\mathrm{e}}$ \\
\hline & & & & & $0.02^{f}$ \\
\hline Regression coefficient $^{\dagger}$ & -4.3 & -2.9 & -2.9 & -2.7 & \\
\hline \multicolumn{6}{|l|}{ Chronic low back pain, mean ${ }^{a}$} \\
\hline No & 47.7 & 47.9 & 49.0 & 49.4 & $0.02^{d}$ \\
\hline
\end{tabular}


Table 5 HRQoL Score According to the Presence or Absence of Health Conditions by Socioeconomic Position, Among Women; National Health Survey (Continued)

\begin{tabular}{|c|c|c|c|c|c|}
\hline Yes & 42.7 & 44.7 & 46.0 & 45.9 & $0.01^{e}$ \\
\hline & & & & & $0.06^{f}$ \\
\hline Regression coefficient $^{\dagger}$ & -4.9 & -3.2 & -3.0 & -3.6 & \\
\hline \multicolumn{6}{|l|}{${ }^{\mathrm{a}}$ : mean adjusted for age } \\
\hline \multicolumn{6}{|c|}{$\begin{array}{l}\text { b: Interaction between health status and years of education: results for years of education }=12 \text { years compared with years of education }<12 \text { years; model } \\
\text { adjusted for age }\end{array}$} \\
\hline \multicolumn{6}{|c|}{$\begin{array}{l}\text { c: Interaction between health status and years of education: results for years of education }>12 \text { years compared with years of education }<12 \text { years; model } \\
\text { adjusted for age }\end{array}$} \\
\hline \multicolumn{6}{|c|}{$\begin{array}{l}\text { d: Interaction between health status and income level: results for income level between 9,900-14,300 } € \text { compared with income level }<9,900 € \text {; model adjusted } \\
\text { for age }\end{array}$} \\
\hline \multicolumn{6}{|c|}{$\begin{array}{l}\text { e: Interaction between health status and income level. Results for income level between } 14,300-20,400 € \text { compared with income level }<9,900 € \text {; model adjusted } \\
\text { for age }\end{array}$} \\
\hline \multicolumn{6}{|c|}{ f: Interaction between health status and income level. Results for income level $>20,400 €$ compared with income level $<9,900 €$; model adjusted for age. } \\
\hline
\end{tabular}

power to put in evidence a significant influence of SEP on the relationship between health status and subjective health.

In our study we used the SF-36 scale as a measure of HRQoL. As observed by Luo et al. health status assessed by different HRQoL indicators is not exactly the same [46]. Even more disturbing for the analysis of social inequalities in health, socioeconomic disparities may vary according to HRQoL indicators used to measure health and indicators used to measure socioeconomic position [11]. Therefore, studies exploring HRQoL with indicators other than the SF-36 are needed.

This study's main strength lies in the fact that the NHS is a national and representative sample and enabled measurement of socioeconomic position by using education and income.

Socially advantaged people were generally at less risk of having or reporting health problems. As expected, SRH and HRQoL were positively associated with SEP. Regardless of health conditions people with lower educational attainment or lower income were more likely than others to report poor SRH and to have poorer quality of life. This gradient was consistent using any of the indicators of SEP, in contrast to the observations of Robert et al. who found that income was more consistently associated with HRQoL and SRH measures among US adults [11].

The presence of a given health condition lowered reported levels of SRH and HRQoL, but the relative impact this condition had on SRH and on HRQoL was different. Regarding SRH, the influence of SEP on the relationship between chronic health conditions and SRH was not consistently significant, but this influence was mainly in the same direction: the impact of chronic health condition, like chronic low back pain, was relatively greater for socially advantaged people. Put differently, people with a high SEP were more likely to report a negative impact of this health condition on their SRH than those with a low SEP. One possible explanation of this finding is that a person's expectations about their health increase with increasing SEP [47]. The repercussions of health problems on SRH would therefore be worse for those with higher health expectations. Another possibility is that one's ability to be aware of one's own health status and to estimate risk is higher in socially advantaged people $[48,49]$. In the event of disease, they are more likely to be aware of the consequences of a health problem, in terms of morbidity or mortality risks, and thus more likely to report poor selfrated health.

In contrast, regarding quality of life, the impact of health conditions on PCS and MCS was lower for socially advantaged people. Shmueli et al. had also showed that, for a same "true health state" (true health considered as a latent variable), individuals in better economic status reported higher health related quality of life than individuals in poor economic status [50]. In our study, among men, the higher their income, the lower its impact on the PCS score, this interaction being less consistent with education. Among women, the same phenomenon was observed for education in case of chronic low back pain. It is noteworthy that income seems to have more influence on the relationship between health conditions and PCS score in men than in women. For MCS score, FL lessened the MCS score for the most highly educated and richest men. Among women, no influence of education was found but the impact on MCS score of chronic low back pain and FL was less pronounced in women with higher income. It is likely that the subjectivity is higher by using SRH, a single item on health in general, than with SF-36 questionnaire, which is a questionnaire with valid items focusing people on specific aspects of health. Therefore it may be a less subjective measure than SRH and less exposed to variability associated with individual health expectations. Moreover quality of life is a broader concept than SRH. 
Several dimensions of life are important, such as subjective well-being, happiness, life satisfaction or social relationships and networks [51]. The notion of resources is probably in part at the origin of this contrast between the two indicators. While perceived health depends on expectations and on comparison with peers, quality of life refers back to an analysis close to that of handicap in opposition to incapacity. Quality of life estimates in a broad way how a disease or disability influences social functioning. In this respect, the notion of financial, social and cultural resources becomes essential to deal with the health conditions. In this context, a high level of resources could limit the impact of a disease on quality of life [52].

\section{Conclusions}

In conclusion, the relationship between subjective health and health conditions is influenced by SEP. This influence depends on the indicators used to measure socioeconomic position. Compared with people in low socioeconomic position, among socially advantaged people some health conditions seem to have a relatively greater impact on SRH, but decrease quality of life to a lesser extent. Therefore, when aiming to analyze social inequalities in health, the use of subjective health indicators could underestimate (SRH) or overestimate (HRQoL) the magnitude of health inequalities existing between socioeconomic groups. Subjective health indicators are not equivalent measures and cannot be used interchangeably. They do not present the same stability as mortality and should be used with caution for analyzing health disparities.

\section{Abbreviations}

SRH: Self-Rated Health; HRQOL: Health Related Quality of Life; SEP: Socioeconomic Position; FL: Functional Limitations; PCS: Physical Component Summary; MCS: Mental Component Summary

\section{Acknowledgements}

We thank the National Institute of Statistics and Economic Studies for enabling us to use the National Health Survey.

This work was supported by the MiRe (Mission de la Recherche) and the Direction of Research, Studies, Evaluation and Statistics, France (R06074BB). The funders had no role in the study design, data collection and analysis, decision to publish, or preparation of the manuscript.

\section{Author details \\ ${ }^{1}$ Inserm, UMR1027, Toulouse, F-31073, France. ${ }^{2}$ Department of public health science, Copenhagen University, Copenhagen, Denmark. ${ }^{3} \mathrm{CHU}$ Toulouse, Department of Epidemiology and Clinical Research, F-31073, France. ${ }^{4}$ Department of Social and Preventive Medicine, Université of Montréal, Montreal, Canada. ${ }^{5}$ Research Center of the Centre hospitalier de I'Université de Montréal, Montreal, Canada. 'Eniversité de Toulouse III, UMR1027, Toulouse, F-31073, France.}

\section{Authors' contributions}

CD, VLC and TL conceived and designed the study. CD and MMP built the database and variables used for the analysis. CD conducted the analysis, helped by BL and VLC and wrote the first draft. MKI and GD contributed to the interpretation of the results and writing the final manuscript. All the authors approved the final version.

\section{Competing interests}

The authors declare that they have no competing interests.

Received: 13 September 2011 Accepted: 10 January 2012

Published: 10 January 2012

\section{References}

1. Mossey JM, Shapiro E: Self-rated health: a predictor of mortality among the elderly. Am J Public Health 1982, 72:800-808.

2. Testa M, Simonson D: Assessment of quality of life outcomes. $N$ Engl J Med 1996, 334:835-840.

3. Idler EL, Benyamini Y: Self-rated health and mortality: a review of twentyseven community studies. J Health Soc Behav 1997, 38:21-37.

4. Singh-Manoux A, Gueguen A, Martikainen P, et al: Self-Rated Health and Mortality: Short- and Long-Term Associations in the Whitehall II Study. Psychosom Med 2007.

5. Otero-Rodriguez A, Leon-Munoz L, Balboa-Castillo T, et al: Change in health-related quality of life as a predictor of mortality in the older adults. Qual Life Res 2010, 19:15-23.

6. Rodriguez-Artalejo F, Guallar-Castillon P, Pascual C, et al: Health-related quality of life as predictor of hospital readmission and death among patients with heart failure. Arch Intern Med 2005, 165:1274-1279.

7. Rumsfeld J, MaWhinney S, McCarthy M, et al: Health-related quality of life as a predictor of mortality following coronary artery bypass graft surgery. participants of the department of veterans affairs cooperative study group on processes, structures, and outcomes of care in cardiac surgery. JAMA 1999, 28:1298-1303.

8. Tsai S, Chi L, Lee C, et al: Health-related quality of life as a predictor of mortality among community-dwelling older persons. Eur J Epidemiol 2007, 22:19-26.

9. Kaplan $M$, Berthelot J, Feeny $D$, et al: The predictive validity of healthrelated quality of life measures: mortality in a longitudinal populationbased study. Qual Life Res 2007, 16:1539-1546.

10. Frybach D, Dunham N, Palta M, et al: US norms for six generic healthrelated quality of life indexes from the National Health Measurement study. Med Care 2007, 45:1162-1170.

11. Robert S, Cherepanov D, Palta M, et al: Socioeconomic status and age variations in health-related quality of life: Results from the national health measurement study. J Gerontol B Psychol Sci Soc Sci 2009, 64:378-389.

12. Mackenbach JP, Stirbu I, Roskam AR, et al: Socioeconomic inequalities in Health in 22 European countries. N Eng J Med 2008, 358:2468-2481.

13. Adams J, White $\mathrm{M}$ : Is the disease risk associated with good self-reported health constant across the socioeconomic spectrum? Public Health 2006, 120:70-75.

14. Festinger L: A theory of social comparison processes. Hum Relat 1954, 7:117-140.

15. Suls J, Wills T: Social comparison: contemporary theory and researc. NJ: Hillsdale; 1991.

16. Ross CE, Van Willigen M: Education and the subjective quality of life. $J$ Health Soc Behav 1997, 38:275-297.

17. Delpierre C, Lauwers-Cances $V$, Datta $G$, et al: Using self-rated health in epidemiological studies: a risk for underestimating the gap between social classes? J Epidemiol Community Health 2009, 63:426-432.

18. Delpierre C, Lauwers-Cances V, Datta G, et al: Impact of social position on the effect of cardiovascular risk factors on self rated health. Am J Public Health 2009, 99:1278-1284.

19. Dowd J, Zajacova A: Does self-rated health mean the same thing across socioeconomic groups? Evidence from biomarker data. Ann Epidemiol 2010, 20:743-749.

20. Van Doorslaer $E$, Gerdtham U: Does inequality in self-assessed health predict inequality in survival by income? Evidence from Swedish data. Soc Sci Med 2003, 57:1621-1629.

21. Smith P, Glazier R, Sibley L: The predictors of self-rated health and the relationship between self-rated health and health service needs are similar across socioeconomic groups in Canada. J Clin Epidemiol 2010, 63:412-421. 
22. Mavaddat N, Kinmonth A, Sanderson S, et al: What determines Self-Rated Health (SRH)? A cross-sectionnal study of SF-36 health domains in the EPIC-Norfolk cohort. J Epidemiol Community Health 2010.

23. Sacker A, Head J, Bartley M: Impact of coronary heart disease on health functioning in an aging population: are there differences according to socioeconomic position? Psychosom Med 2008, 70:133-140.

24. Allonier C, Guillaume S, Sermet C: De quoi souffre-t-on? Etat des lieux des maladies déclarées en France. Enquête décennale santé INSEE 20022003. Bulletin d'information en économie de la santé 2007, 123:1-6.

25. Blane D, Netuveli G, Montgomery S: Quality of life, health and physiological status and change at older ages. Soc Sci Med 2008, 66:1579-1587

26. Singh-Manoux A, Martikainen $P$, Ferrie J, et al: What does self rated health measure? results from the British Whitehall II and French Gazel cohort studies. J Epidemiol Community Health 2006, 60:364-372.

27. Katz S, Ford A, Moskowitz R, et al: Studies of illness in the aged: the index of $A D L$, a standardized measure of biological and psychosocial function. J Am Med Assoc 1963, 185:914-919.

28. Kuorinka I, Jonsson B, Kilbom A, et al: Standardised Nordic questionnaire for the analysis of musculoskeletal symptoms. App/ Ergon 1987, 18:233-237.

29. Leclerc A, Gourmelen J, Chastang J, et al: Level of education and back pain in France: the role of demographic, lifestyle and physical work factors. Int Arch Occup Environ Health 2009, 82:643-652.

30. Ware J, Snow K, Kosinski M, et al: SF-36 health survey manual and interpretation guid. Boston: New England Medical Center; 1993.

31. Jenkinson C: Comparison of UK and US methods for weighting and scoring the SF-36 summary measures. J Public Health Med 1999, 21:372-376.

32. Cott CA, Gignac MA, Badley EM: Determinants of self rated health for Canadians with chronic disease and disability. J Epidemiol Community Health 1999, 53:731-736.

33. Borrell C, Muntaner C, Benach J, et al: Social class and self-reported health status among men and women: what is the role of work organisation, household material standards and household labour? Soc Sci Med 2004, 58:1869-1887.

34. Esteban Y, Pena M, Hernandez Barrera V, Fernandez Cordero X, et al: Selfperception of health status, mental health and quality of life among adults with diabetes residing in a mertopolitan area. Diabetes Metab 2010.

35. Macintyre S, Ford G, Hunt K: Do women 'over-report' morbidity? Men's and women's responses to structured prompting on a standard question on long standing illness. Soc Sci Med 1999, 48:89-98.

36. Soltoft F, Hammer M, Kragh N: The association of body mass index and health-related quality of life in the general population: data from the 2003 Health Survey of England. Qual Life Res 2009, 18:1293-1299.

37. Jylha M, Volpato S, Guralnik JM: Self-rated health showed a graded association with frequently used biomarkers in a large population sample. J Clin Epidemiol 2006, 59:465-471.

38. Jurges $\mathrm{H}$ : True health vs response styles: exploring cross-country differences in self-reported health. Health Econ 2007, 16:163-178.

39. Merkin S, Cavanaugh K, Longenecker J, et al: Agreement of self-reported comorbid conditions with medical and physician reports varied by disease among end-stage renal disease patients. J Clin Epidemiol 2007, 60:634-642.

40. Kriegsman D, Penninx B, van Eijk J, et al: Self-reports and general practitioner information on the presence of chronic diseases in community dwelling elderly. a study on the accuracy of patient's selfreports and on determinants of inaccuracy. J Clin Epidemiol 1996, 49:1407-1417.

41. Haapanen N, Miilunpalo S, Pasanen M, et al: Agreement between questionnaire data and medical records of chronic diseases in middleaged and elderly Finnish men and women. Am J Epidemiol 1997, 145:762-769.

42. Idler $E$, Leventhal H, McLaughlin J, et al: In sickness but not in health: selfratings, identity, and mortality. J Health Soc Behav 2004, 45:336-356.

43. Shmueli A: Reporting heterogeneity in the measurement of health and health-related quality of life. Pharmacoeconomics 2002, 20:405-412.

44. Selvin S: Statistical analysis of epidemiological dat. New York: Oxford University Press ed; 1996.
45. Marshall S: Power for tests of interaction: effect of raising the Type I error state. Epidemiol Perspect Innov 2007, 19:1-7.

46. Luo N, Johnson J, Shaw J, et al: Self-reported health status of the general adult US population as assessed by the EQ-5D and Health Utilities Index. Med Care 2005, 43:1078-1086.

47. Brouwer WB, van Exel NJ: Expectations regarding length and health related quality of life: some empirical findings. Soc Sci Med 2005, 61:1083-1094.

48. Frijling B, Lobo C, Keus I, et al: Perceptions of cardiovascular risk among patients with hypertension or diabetes. Patient Educ Couns 2004, 52:47-53.

49. Eachus J, Pearson N, Propper C, et al: An additional dimension to health inequalities: disease severity and socioeconomic position. J Epidemiol Community Health 1999, 53:603-611.

50. Shmueli A: Socio-economic and demographic variation in health and in its measures: the issue of reporting heterogeneity. Soc Sci Med 2003, 57:125-134.

51. Netuveli G, Blane D: Quality of life in older ages. Brit Med Bull 2008, 85:113-126.

52. Frohlich $\mathrm{K}$, Corin $\mathrm{H}$, Potvin L: A theoretical proposal for the relationship between context and disease. Sociol Health IIIn 2001, 23:776-797.

\section{Pre-publication history}

The pre-publication history for this paper can be accessed here: http://www.biomedcentral.com/1471-2458/12/19/prepub

doi:10.1186/1471-2458-12-19

Cite this article as: Delpierre et al:: SRH and HrQOL: does social position impact differently on their link with health status? BMC Public Health 2012 12:19

\section{Submit your next manuscript to BioMed Central and take full advantage of:}

- Convenient online submission

- Thorough peer review

- No space constraints or color figure charges

- Immediate publication on acceptance

- Inclusion in PubMed, CAS, Scopus and Google Scholar

- Research which is freely available for redistribution

Submit your manuscript at www.biomedcentral.com/submit
C) Biomed Central 